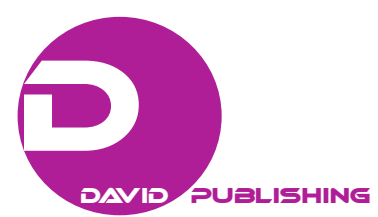

\title{
The Importance of Strategic Analysis in Investment Appraisal
}

\author{
Nuno Moutinho \\ Polytechnic Institute of Bragança, Porto, Portugal \\ Helena Mouta \\ Risk, Planning and Research Unit, IFD, Porto, Portugal
}

\begin{abstract}
A company's investment promotes the creation of shareholder value, so an adequate analysis of all factors that may interfere with its viability is relevant. For the evaluation of a given project, financial criteria and non-financial criteria should be used. Here, we highlight the importance of the strategic aspects for the investment decision and the importance of synergies and consistency with the strategic objectives of the company. The strategic analysis of investments is relevant to understand the combined effect with the project sponsor. In this sense, these issues are crucial in investment decisions, which is explained by the risks associated with an inadequate analysis. We also present the main strategic risks and how to minimize them.
\end{abstract}

Keywords: strategic analysis, project evaluation, non-financial criteria

\section{Introduction}

A company can choose, strategically, one of three situations: buying competencies, capacities, and resources; outsourcing (allows flexibility and speed); and developing those skills internally (allows for secrecy, exclusivity, and surprise). If the company chooses the latter, it will have to implement investment projects that allow it to reach such objectives.

The strategy defined for a project should lead the company to the objectives outlined. In strategic terms, a project must result from the play of the threats and opportunities of the environment and the company's strengths and weaknesses (Goll \& Sambharya, 1998). This analysis makes it possible to clarify issues, identify preferred and likely courses of action, and to carry out a general and rapid analysis of the potential, i.e., to help better understand the project. It also seeks to help the actors to know what they are getting involved in and why. Therefore, an analysis of external and internal conditions should be carried out to verify the feasibility of the project, particularly in the medium- and long-term (Pettinger, 2003).

This paper is organized as follows. In the next section, we present a discussion of the topic, followed by the strategic risk factors. Then, we analyze the main procedures for minimizing strategic risks, and follow with a proposal for understanding how companies have perceived the importance of this topic and how they act when they make investment decisions. We finish by presenting the conclusion.

\section{Framework}

Nuno Moutinho, Ph.D., Department of Economics and Management, Polytechnic Institute of Bragança, Bragança, Portugal. Helena Mouta, master, Risk, Planning and Research Unit, IFD, Porto, Portugal.

Correspondence concerning this article should be addressed to Nuno Moutinho, Instituto Politécnico de Bragança, Escola Superior de Tecnologia e Gestão, Campus de Santa Apolónia, Gabinete 63, Bragança 5300-253, Portugal. 
In this dimension, the approach to be taken should encompass the evaluation of three aspects that allow an integrated vision of the project in the company: strategy, synergy, and risk.

As for the strategy, since the projects are a way to implement the company's strategy, its objectives must be directly related to the strategic objectives of the company (Kenny, 2003). Several authors point out that investments must be consistent with each other and with the company's overall corporate and functional objectives in both the short and long term (Shenhar, Dvir, Levy, \& Maltz, 2001; Tayles \& Drury, 2001).

Since a project must be consistent with the company's strategy, only those that are critical to the company's development should be adopted (Wheelwright \& Clark, 1992). Lefley (1996) pointed out that the evaluation of projects must be made in the light of the strategic business culture, and strategic alignment of projects is essential (Turner, Keegan, \& Crawford, 2000). White and Fortune (2002) pointed out the need to integrate the project into the company and to verify the project's consequences for the company's business performance. Thus, a project may be appropriate for one company and not for another (Lopes \& Flavell, 1998).

Keegan and Turner (2000) and Walls (1995) argued that projects should combine synergies with the business of the company. Along the same lines, Lopes and Flavell (1998) emphasized the high importance of the project's compatibility with the existing activities in the company and the benefits of their combination. Thus, in a project, the activities should be focused on the business needs and the creation of competitive advantage for the company (Shenhar et al., 2001).

As for the project's risk level, Lopes and Flavell (1998) showed that caution should be taken with the project's specific risk level and the company's capacity to withstand it. From this perspective, it is important to ascertain the impact of the project on the overall risk of the company, as it may be preferable to carry out a number of small-scale projects with a low risk, instead of a large project with a high risk for the company.

\section{Strategic Risk Factors}

Anderson and Merna (2003) reported that an inappropriate or poor management of the project at the initial design stage creates unnecessary risks (deviations from the strategic objectives initially proposed), with inevitable consequences of poor performance. The alternative should be based on understanding and respect for project management and on the ability of project managers to take on their responsibilities.

Lopes and Flavell (1998) highlighted the main strategic risk factors. First, the lack of an integrated vision of the business can lead to problems, such as the underutilization of its resources and its better capabilities, as well as the duplication of some tasks, reflecting the company's performance. In effect, the company runs a serious risk of business fragmentation. On the other hand, the problems of non-synergies between the project and the other activities in the company may lead to incompatibility and inconsistency between business units. Another type of risk for the company is the concentration of risk, due to the implementation of a large project, when compared to the size of the company.

\section{Strategic Risk Minimization}

As a way to address the risk of business fragmentation, an integrated business vision must be created. The company must previously and clearly define concrete objectives and priorities and its strategy should be reviewed throughout the project (Lopes \& Flavell, 1998).

Concerning the risk of incompatibility, consistency should be sought between all the units involved and the choice of projects should be made taking into account the existence of at least some synergies in order to 
benefit from the knowledge and experience already gained (Lopes \& Flavell, 1998).

In order to minimize ambiguities and conflicts during the implementation of a project, Ling and Lau (2002) highlighted the importance of dividing a large and complex project into several small projects, for which the best specialists can be subcontracted to each of the areas developed. For Lopes and Flavell (1998), the company must be able to analyse its risk-bearing capabilities in order to control the inherent uncertainties. It is necessary to know the type of risks that the company is willing to bear and, at the same time, to know clearly what types of projects the company is able to implement-projects should only be implemented in areas where the company is strong.

It may also be important to diversify the sources of risk. If the company diversifies risk across multiple areas (geographical, political, technical, etc.), it dilutes the concentration of risk and the likelihood of something going wrong.

\section{Assessment of Strategic Aspects}

For Lopes and Flavell (1998), the evaluation of strategic factors should be done as soon as possible and precede any other type of evaluation. The goal is not to waste resources in more advanced phases without major (initial) strategic decisions being resolved. Since these decisions are taken early in the life cycle of the project, it is important that, over time, revisions are made to the initial decisions, to adapt to the changing circumstances of the project. The assessment of strategic factors should be conducted by senior experts with a strong strategic vision and extensive experience in risk issues. On the other hand, all units of the company must be present in this analysis to ensure coordination and consistency of the project with the various areas of the company. It is therefore important that all departments are consulted and feedback from the various experts is obtained in a timely manner in order to analyse all the details.

Wheelwright and Clark (1992) added that it is not right or appropriate to assign only one department the single responsibility for starting all projects because it is generally not in a position to analyse the strategic importance of all projects.

\section{Strategic Thinking of Companies}

The analysis of the strategic aspects in a project is relevant to perceive its limits, as well as the synergies of the project with the development of the business of the company that supports it.

In a field work for Portuguese companies, Moutinho and Lopes (2011a) found evidence that the strategic aspects of the projects are the most relevant factors in investment appraisal. These aspects seem even more relevant than the financial ones.

As in Kenny (2003), Cooke-Davies (2002), and Lopes and Flavell (1998), in a more detailed study, Moutinho and Lopes (2011b) showed that the contribution of the project to the company's strategic goals is the most relevant characteristic in project valuation. The companies also carefully analyse the impact on the company's global risk and the impact on future projects. Alkaraan and Northcott (2006) also showed that strategic issues are very important, and the most relevant strategic criteria are those that are perceived as being related to financial results.

Regarding the importance attributed to the goals in the decision to proceed with the project, Moutinho and Lopes (2011b) showed that the development of company's current business, exploring opportunities/strengths, meeting the market's needs and profit maximization are the most important goals in 
investment appraisal.

The writers also point out that the most important strategic risk factors are the use of new resources and the strategic complexity of the project.

Moutinho and Lopes (2011b) also presented a set of procedures used by Portuguese companies to minimize potential strategic risks. The main procedures identified are a clear a priori definition of goals, analysing the capability to implement the project, the definition of priorities and the choice of projects with synergies.

\section{Conclusion}

The strategic analysis in investment appraisal is fundamental as a way of understanding if the existing synergies which allow the company to leverage the benefits of the project.

This paper analyses the relevance of strategic aspects for investment decision and it is clear that these issues are crucial in the decisions, which is explained by the risks associated with an inadequate analysis and with the procedures to minimize them.

In spite of the evidence found for the Portuguese companies, which highlights strategic factors and suggestions for future study include the analysis of the importance of these factors in companies from other countries.

\section{References}

Alkaraan, F., \& Northcott, D. (2006). Strategic capital investment decision-making: A role for emergent analysis tools? A study of practice in large UK manufacturing companies. The British Accounting Review, 38, 149-173.

Anderson, D., \& Merna, T. (2003). Project management strategy_Project management represented as a process based set of management domains and the consequences for project management strategy. International Journal of Project Management, 21(6), 387-393.

Cooke-Davies, T. (2002). The "real" success factors on projects. International Journal of Project Management, 20(3), $185-190$.

Goll, I., \& Sambharya, R. (1998). Rational model of decision-making, strategy, and firm performance. Scandinavian Journal of Management, 14(4), 479-492.

Keegan, A., \& Turner, J. (2000). The management of innovation in project based firms. Report Series Research in Management, 57. Retrieved from https://repub.eur.nl/pub/65/erimrs20001219085956.pdf

Kenny, J. (2003). Effective project management for strategic innovation and change in an organizational context. Project Management Journal, 34(1), 43-53.

Lefley, F. (1996). Strategic methodologies of investment appraisal of AMT projects: A review and synthesis. The Engineering Economist, 41(4), 345-363.

Ling, Y., \& Lau, B. (2002). A case study on the management of the development of a large-scale power plant project in East Asia Based on design-build arrangement. International Journal of Project Management, 20(6), 413-423.

Lopes, M., \& Flavell, R. (1998). Project appraisal—A framework to assess non-financial aspects of projects during the project life cycle. International Journal of Project Management, 16(4), 223-233.

Moutinho, N., \& Lopes, M. (2011a). The relative importance of financial and non-financial analysis in project evaluation-Evidence from Portuguese firms. FMA European Conference, 8-10 June 2011, Porto, Portugal.

Moutinho, N., \& Lopes, M. (2011b). Non-financial analysis in project appraisal—An empirical study. 2011 Annual Conference of European Financial Management Association, 22-25 June, Braga, Portugal.

Pettinger, R. (2003). A decisão de investimento. Lisboa: Prefácio.

Plath, S., \& Kukil, K. V. (2000). The unabridged journals of Sylvia Plath, 1950-1962. New York: Anchor Books.

Shenhar, A., Dvir, D., Levy, O., \& Maltz, A. (2001). Project success: A multidimensional strategic concept. Long Range Planning, 34(6), 699-725.

Tayles, M., \& Drury, C. (2001). Moving from make/buy to strategic sourcing: The outsource decision process. Long Range Planning, 34(5), 605-622. 
Turner, J., Keegan, A., \& Crawford, L. (2000). Learning by experience in the project-based organization. Report Series Research in Management, 58. Retrieved from https://repub.eur.nl/pub/66/erimrs20001219091359.pdf

Walls, M. (1995). Integrating business strategy and capital allocation: An application of multi-objective decision-making. The Engineering Economist, 40(3), 247-266.

Wheelwright, S., \& Clark, K. (1992). Creating project plans to focus product development. Harvard Business Review, March-April, 70-82.

White, D., \& Fortune, J. (2002). Current practice in project management-An empirical study. International Journal of Project Management, 20(1), 1-11. 